\title{
Effect of Interferon- $a$ and Combined Interferon- $a$ with Lamivudine Treatment on Anthropometric Measurements in Children with Chronic Hepatitis B
}

\author{
Nafiye Urgancia ${ }^{a}$ Derya Kalyoncu ${ }^{b, c}$ Ela Erdem Eralp ${ }^{b}$ \\ ${ }^{a}$ Division of Pediatric Gastroenterology, and ${ }^{\mathrm{b}}$ Department of Pediatrics, Sisli Etfal Training and Research Hospital, and \\ 'Istinye State Hospital, Pediatrics, Istanbul, Turkey
}

A total of 43 children with chronic hepatitis B aged from 2 to 17 years were tested for anthropometric measurements such as weight, height, mid-arm circumference (MAC), mid-arm muscle area (MAMA), body mass index, triceps skin-fold thickness and subscapular skin-fold thickness (SST) every month following initiation of treatment for this condition.

When the initial pretreatment anthropometric measurements of both groups (patients whom only interferon- $\alpha$ (IFN- $\alpha$ ) given and patients whom combination treatment given) were compared, no statistically significant difference was observed in terms of height, weight, body mass index, MAC, SST, and MAMA Z-scores $(p>0.05)$. Thirteen patients had malnutrition (30\%) and $16 \%$ of them had obesity. When the association between the HBeAg-positive and anti-HBe-positive patients and the anthropometric measurements at the end of the treatment were evalu- ated in each group, TST and SST Z-scores of HBeAg-positive patients were significantly higher than those in anti-HBe positive patients in group $1(p<0.05)$. No statistically significant differences were observed in the other Z-scores $(p>0.05)$. When HBeAg-positive patients and antiHBe-positive patients were compared in group 2, TST, SST, MAC, and MAMA Z-scores were not found to be statistically different $(p>$ 0.05 ; Table 1). Also, no correlation was established between HAI and Z-scores of anthropometric measurements $(p>0.05)$.

There are a limited number of studies assessing the anorexia and weight loss during the treatment of hepatitis $B$ reporting that no change was observed in weight or it returned to normal after the discontinuation of the treatment [1-4]. Although there are studies about treatment with IFN- $\alpha$ and its effect on growth, there is only one report from Turkey

Table 1. Anthropometric measurements of patients based on treatment response in groups 1 and 2

\begin{tabular}{|c|c|c|c|c|c|c|}
\hline & \multicolumn{3}{|c|}{ Group $1(\mathrm{LAM}+\mathrm{INF}-\alpha)$} & \multicolumn{3}{|c|}{ Group 2 (INF- $\alpha)$} \\
\hline & HBeAg & anti-HBe & $p$ value & HBeAg & anti-Hbe & $p$ value \\
\hline Height Z-score & $-0.14 \pm 1.06$ & $-0.65 \pm 1.39$ & 0.374 & $-0.25 \pm 1.63$ & $-0.43 \pm 1.10$ & 0.795 \\
\hline Weight Z-score & $-0.18 \pm 0.52$ & $-0.35 \pm 1.06$ & 0.627 & $-0.24 \pm 0.70$ & $-0.35 \pm 0.71$ & 0.738 \\
\hline TST Z-score & $-0.45 \pm 0.45$ & $-1.31 \pm 0.67$ & 0.002 & $-0.39 \pm 0.56$ & $-0.39 \pm 0.87$ & 0.981 \\
\hline SST Z-score & $0.08 \pm 0.35$ & $-0.35 \pm 0.44$ & 0.025 & $0.08 \pm 0.42$ & $0.44 \pm 1.01$ & 0.265 \\
\hline MAC Z-score & $-0.10 \pm 0.97$ & $-0.08 \pm 1.71$ & 0.974 & $-0.09 \pm 0.68$ & $-0.18 \pm 1.62$ & 0.730 \\
\hline BMI Z-score & $0.17 \pm 0.59$ & $-0.03 \pm 0.64$ & 0.476 & $0.24 \pm 0.80$ & $0.18 \pm 0.84$ & 0.877 \\
\hline MAMA Z-score & $0.31 \pm 1.30$ & $1.03 \pm 2.80$ & 0.410 & $0.40 \pm 1.02$ & $0.33 \pm 2.75$ & 0.928 \\
\hline
\end{tabular}

\section{KARGER}

(c) 2017 S. Karger AG, Basel

E-Mail karger@karger.com

www.karger.com/anm 
conducted by Ozturk et al. [5] about the association between different treatment protocols and nutritional status. In this study, 32 children with $\mathrm{CHB}$ were divided into 3 groups according to the given treatment. Only IFN- $\alpha$ was given for 6 months to the first group, LAM was given for 2 years to the second group, and combined IFN with LAM was given to the third group. Those in the first and the third groups who were given only IFN- $\alpha$ and combination treatment were found to have decreased weight in the first month of follow-up. They observed that decrease in the weight was not permanent and concluded that there was no relation between anthropometric measurements and the treatment regimens. In our study, similarly, no significant difference was observed based on the different treatment regimens followed. Also, HBeAg -positive patients and anti-

\section{References}

1 Comanor L, Minor J, Conjeevaram HS, Roberts EA, Alvarez F, Bern EM, et al: Impact of chronic hepatitis $B$ and interferon-alpha therapy on growth of children. J Viral Hepat 2001; 8:139-147.

2 Lebensztejn DM, Zagórecka E, Kaczmarski M, Piotrowska-Jastrzebska J: [The assessment of nutritional status in children with chronic hepatitis B treated with interferon alpha]. Pol Merkur Lekarski 2001;11:29-31.
HBe positive patients were compared in our study and significant difference was observed between these groups only in terms of TST and SST scores at the end of the treatment. This can be explained by the fact that 5 overweight/obese children were included in group 1 and 2 children in group 2 randomly. We could not, however, explain the reason for the no response observed to the treatment given in overweight/obese children - whether it was due to steatohepatitis or insulin resistance. Although no significant difference was observed in the HAI and fibrosis lev$\mathrm{el}$, it is noteworthy that none of them had anti-HBe seroconversion. Bekem Soylu et al. [6] have reported that there was no relation between HAI and the anthropometric measurements. In line with the results of this study, we too observed no significant difference in our study.
In conclusion, it is known that the nutritional status of the children with $\mathrm{CHB}$ is affected first due to the disease itself and then due to the treatment (IFN) given. No association was established between nutritional status, anthropometric measurements, and treatment regimens except triceps skin-fold thickness and SST Z-scores of HBeAg-positive patients who treated with combined IFN- $\alpha$ and lamivudin. The problem of weight loss gets rectified with the discontinuation of the treatment.

\section{Disclosure Statement}

The authors have no conflicts of interest.

\section{Funding}

The authors have received no funding for this work.
3 Kuloğlu Z, Kansu A, Demirçeken F, Arici ZS, Berberoğlu M, Ocal G, et al: The influence of interferon-alpha and combination interferon-alpha and lamivudine therapy on height and weight in children with chronic hepatitis B infection. J Pediatr Endocrinol Metab 2007; 20:615-620.

4 Knodell RG, Ishak KG, Black WC, Chen TS, Craig R, Kaplowitz N, et al: Formulation and application of a numerical scoring system for assessing histological activity in asymptomatic chronic active hepatitis. Hepatology 1981;1:431-435.
5 Ozturk Y, Arli AO, Arslan N, Bekem O, Hizli $S$, Buyukgebiz B: Influences of different therapy protocols for chronic hepatitis $b$ infection in Turkish children on nutritional anthropometric data. J Health Popul Nutr 2004;22:443-444.

6 Bekem Soylu O, Targan S, Diniz G, Ortac R: Nutritional status of children with chronic hepatitis B in a population with low socioeconomic status. Eur J Gastroenterol Hepatol 2009;21:1252-1255.
Effect of IFN- $\alpha$ and Combined IFN- $\alpha$ with Lamivudine Treatment
Ann Nutr Metab 2017;71:8-9 DOI: $10.1159 / 000478033$ 